\title{
Ocular, cerebral and systemic interrelationships of cytomegalovirus infection in a post- mortem study of AIDS patients
}

\begin{abstract}
Purpose Eighty-six post-mortems of AIDS patients were reviewed microscopically and the presence of cytomegalovirus (CMV) infection in the viscera, brain and eye was recorded.

Methods Immunohistochemical stains and in situ hybridisation with a CMV probe were performed.

Results and conclusion CMV infection was observed in $63 \%$ of the cases. Visceral, cerebral and ocular involvement were overall $49 \%, 33 \%$ and $29 \%$, respectively. The visceral form with no concomitant ocular and/or cerebral infection was the main cause of death $(31 \%)$ in the $54 \mathrm{CMV}$-infected patients. Although CMV retinitis occurred mostly $(20 \%)$ as a component of systemic disease, in $13 \%$ of the CMVinfected patients the eyes only were involved, while there were no cases with CMV limited to the brain. In the absence of systemic involvement, $9 \%$ of the cases showed concomitant ocular and cerebral infection, but because we failed to observe CMV optic neuritis without ocular involvement, retrograde viral spread from the brain through the optic nerve appears to be an infrequent mechanism of CMV retinitis.
\end{abstract}

Key words AIDS, CMV infection, CNS, Eye, Post-mortem

Acquired cytomegalovirus (CMV) infection in the adult is usually the result of an immunocompromised state. At present, the vast majority of cases are AIDS-related, CMV retinitis being the most common sightthreatening infection in this patient population (12-46\% of cases). ${ }^{1}$ In immunosuppressed individuals CMV retinitis can either occur from the outset as part of a multi-organ involvement, or be the only initial clinical sign of systemic CMV disease, ${ }^{2,3}$ in addition, a number of
I. PECORELLA, A. CIARDI,

A. CREDENDINO, A. MARASCO,

U. DI TONDO, F. SCARAVILLI acquired CMV infections were recently noted to manifest exclusively as retinitis. ${ }^{1,4.5}$ However, as the latter studies are based on clinical observations only, the possibility of other minor systemic CMV infections was not ruled out. To date, only four other autopsy studies ${ }^{6-9}$ have reported cumulative data on the presence of CMV in the eye, brain and viscera, and another ${ }^{10}$ in the brain and eye; however, in these studies either the number of patients investigated was small $(25,35$ and 43, respectively, in De Girolami's, Pepose's and Jensen's studies ${ }^{6,8,10}$ and the authors made no attempt to draw conclusions, or the reported data on the non-ocular sites of CMV involvement are insufficient. ${ }^{7,9}$ Nevertheless, in De Girolami's and Morinelli's study ${ }^{6,7} \mathrm{CMV}$ retinitis was documented in $12 \%$ and $6.3 \%$ of the cases, respectively, in the absence of other tissue involvement.

The aims of the present study were: (1) to determine the incidence of CMV retinitis in a large series of AIDS post-mortems; (2) to correlate CMV retinitis with visceral and cerebral involvement; and (3) to ascertain whether CMV retinitis can occur in the absence of CMV infection elsewhere, or which of the various complications are more commonly associated with it.

\section{Materials and methods}

Our series is composed of a cohort of 86 consecutive post-mortems of patients dying with AIDS, performed over a period of 4 years (1992-6) partly in London and partly in Rome, regardless of whether there was a history of ocular involvement. All patients but one were male, ranging in age from 22 to 59 years (mean age 38.8 years). Seventy-two patients were British homosexual or bisexual, and 14 Italian heterosexual with a history of exposure to other risk factors such as drugs, transfusion and HIVinfected partner(s). Apart from 3 British

\author{
I. Pecorella \\ A. Ciardi \\ A. Credendino \\ A. Marasco \\ U. Di Tondo \\ Department of Experimental \\ Medicine and Pathology \\ University of Rome \\ "La Sapienza" \\ Rome, Italy \\ F. Scaravilli \\ Department of \\ Neuropathology \\ Institute of Neurology, UCL \\ London, UK
}

Irene Pecorella, MD

Dipartimento di Medicina

Sperimentale e Patologia

Policlinico Umberto I

Viale Regina Elena, 324

I-00161 Rome, Italy

Received: 16 March 1998 Accepted in revised form: 4 June 1999 
Table 1. Cytomegalovirus infection in the ocular, visceral and cerebral compartments in 54 AIDS post-mortems

\begin{tabular}{lcc}
\hline Compartment & No. of patients & $\%$ \\
\hline Visceral only & 17 & 31 \\
Visceral and cerebral & 12 & 22 \\
Visceral, cerebral and ocular & 11 & 20 \\
Ocular only & 7 & 13 \\
Ocular and cerebral & 5 & 9 \\
Ocular and visceral & 2 & 4 \\
\hline
\end{tabular}

individuals from the West Indies (Barbados, Jamaica, Trinidad), all the cases were white. The notes were available for 47 patients and were reviewed retrospectively with regard to the ophthalmological findings in the last year of life.

In all cases a full post-mortem was performed that included removal of one or both (12 cases) eyes. In total, 98 eyes provided with a short segment of the optic nerve were collected and fixed in $10 \%$ formol saline.

Conventional horizontal cuts were made to remove superior and inferior calottes before standard processing and sectioning at a minimum of three levels. Any calotte in which lesions were visible on dissection microscopic examination were also processed to paraffin embedding.

The brain was serially cut coronally at $1 \mathrm{~cm}$ intervals before processing to paraffin and a minimum of 13 standard samples were taken.

The eyes, brains and viscera with microscopical features of CMV infection were subjected to in situ hybridisation with a CMV probe (Enzo Diagnostics). Immunohistochemical search for opportunistic infections other than CMV included Toxoplasma gondii (Biogenex) and herpes simplex virus type 1 and 2 (Dako).

Immunohistochemistry was performed using a standard biotin-streptavidin-peroxidase technique.

For in situ hybridisation, $5 \mu \mathrm{m}$ sections were cut onto silane-coated slides and placed on a hot-plate for 12-16 h. The sections were dewaxed and rehydrated in warm xylene for $30 \mathrm{~min}$, cold xylene for $10 \mathrm{~min}, 100 \%$ alcohol $2 \times$ for $10 \mathrm{~min}$, incubated in $0.6 \%$ hydrogen peroxide in $80 \%$ methanol for $20 \mathrm{~min}$ to inhibit endogenous peroxidase activity, rinsed in deionised water over $30 \mathrm{~min}$ and then placed in phosphate-buffered saline (PBS) for $5 \mathrm{~min}$. Sections were then immersed in PBS containing $0.01 \%$ Triton-X100 for $90 \mathrm{~s}$, washed in PBS for $5 \mathrm{~min}$, and immersed in $50 \mathrm{mM}$ Tris- $\mathrm{HCl}$ ( $\mathrm{pH}$ 7.6) $5 \mathrm{mM}$ EDTA prewarmed to $42{ }^{\circ} \mathrm{C}$ for $2 \mathrm{~min}$ (proteinase $\mathrm{K}$ buffer). The slides were transferred to an incubation tray and the sections covered with a few drops of the proteinase $\mathrm{K}$ buffer as above containing $0.5 \mathrm{mg} / \mathrm{ml}$ of proteinase $\mathrm{K}$ which was pre-warmed to $42{ }^{\circ} \mathrm{C}$. The incubation tray was then placed in a $37^{\circ} \mathrm{C}$ incubator for $10 \mathrm{~min}$. Digestion was stopped with several changes, $5 \mathrm{~min}$ each, of ice-cold PBS. Post-fixation of the sections was carried out in $4 \%$ paraformaldehyde in PBS for $5 \mathrm{~min}$, and the slides were washed again in PBS for $5 \mathrm{~min}$. Dehydration took place through graded alcohols and the sections were allowed to dry at room temperature. Seventy-five microlitres of the CMV probe in hybridisation buffer (containing $2 \times$ SSC, $5 \%$ dextran sulphate, $0.2 \%$ milk powder and $50 \%$ formamide) was applied to the centre of the slide and the sections covered with a sialinated coverslip. The slides were placed on a pre-heated baking tray and incubated at $90^{\circ} \mathrm{C}$ for $10 \mathrm{~min}$. The slides were then transferred to a humidified box and incubated at room temperature for $1 \mathrm{~h}$. The coverslip was removed using a scalpel blade to lift a corner and the slides washed in $2 \times$ SSC at $60{ }^{\circ} \mathrm{C}$ for $20 \mathrm{~min}$ with agitation; $0.2 \times$ SSC at $42{ }^{\circ} \mathrm{C}$ for 20 min with agitation; $0.1 \times$ SSC with $10 \%$ formamide at room temperature for $5 \mathrm{~min} ; 2 \times \mathrm{SSC}$ at room temperature for $5 \mathrm{~min}$. The slides were then transferred into $0.1 \mathrm{M}$ Trisbuffer saline (TBS) for $5 \mathrm{~min}$, and incubated at room temperature in $3 \%$ bovine serum albumin for $15 \mathrm{~min}$. The excess buffer was wiped from the slides and a few drops of TBS containing mouse anti-biotin 1:200 (Dako) added to each section for $20 \mathrm{~min}$. The slides were washed with agitation with two changes of TBS for 10 min each and returned to the incubation tray. A few drops of TBS containing biotinylated sheep anti-mouse 1:50 (Amersham) were added to each section and incubated at room temperature for $20 \mathrm{~min}$, then washed with agitation twice with TBS for $10 \mathrm{~min}$ each. The slides were returned to the incubation tray and the sections covered with the streptavidin-peroxidase complex (Amersham) 1:300 for $20 \mathrm{~min}$, washed with agitation twice with TBS for $10 \mathrm{~min}$ each and incubated in TBS containing 0.05\% 3,3-

diaminobenzidine tetrahydrochloride (DAB) (Sigma) and $0.03 \%$ hydrogen peroxide. Monitoring of colour development took place in the dark after $5 \mathrm{~min}$ and then continuously until development appeared complete. The sections were rinsed in distilled water, counterstained with haematoxylin, rinsed in distilled water, dehydrated in graded alcohols, cleared in xylene and mounted with resin.

For the purpose of this study, three sites of CMV infection were considered: eye, brain and viscera. The total number of infections in each site, as well as the concomitant involvement of one or both of the other compartments, were recorded (Table 1).

\section{Results}

CMV was diagnosed morphologically by the presence of the characteristic 'owl's eye' cells and cytoplasmic viral inclusions (Fig. 1). In the 25 eyes with microscopical features of CMV, infected cells appeared to affect the full

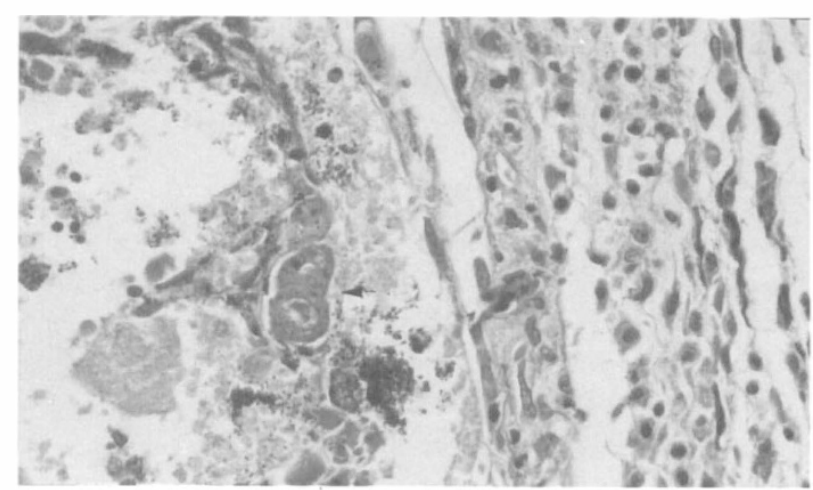

Fig. 1. Active CMV chorioretinitis. The retina (left) is totally necrotic and contains giant cells with intranuclear inclusion bodies surrounded by a clear halo (arrowhead). The choroid (right) is severely inflamed. $H \mathcal{E} E, \times 400$. 


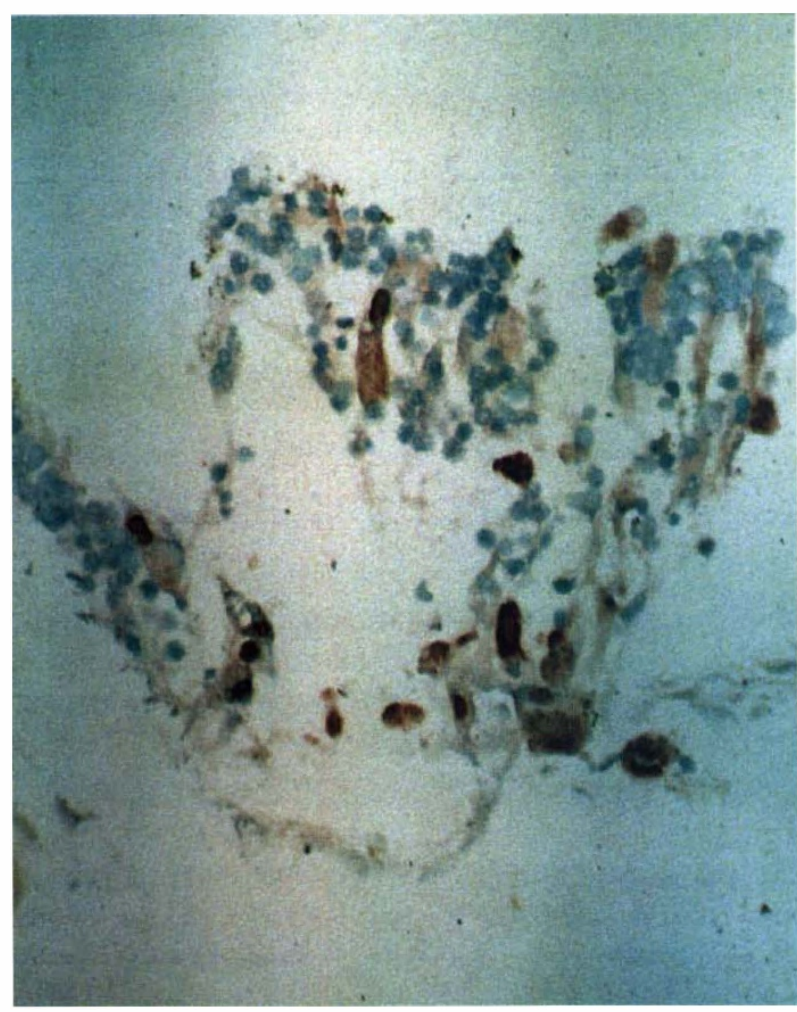

(a)

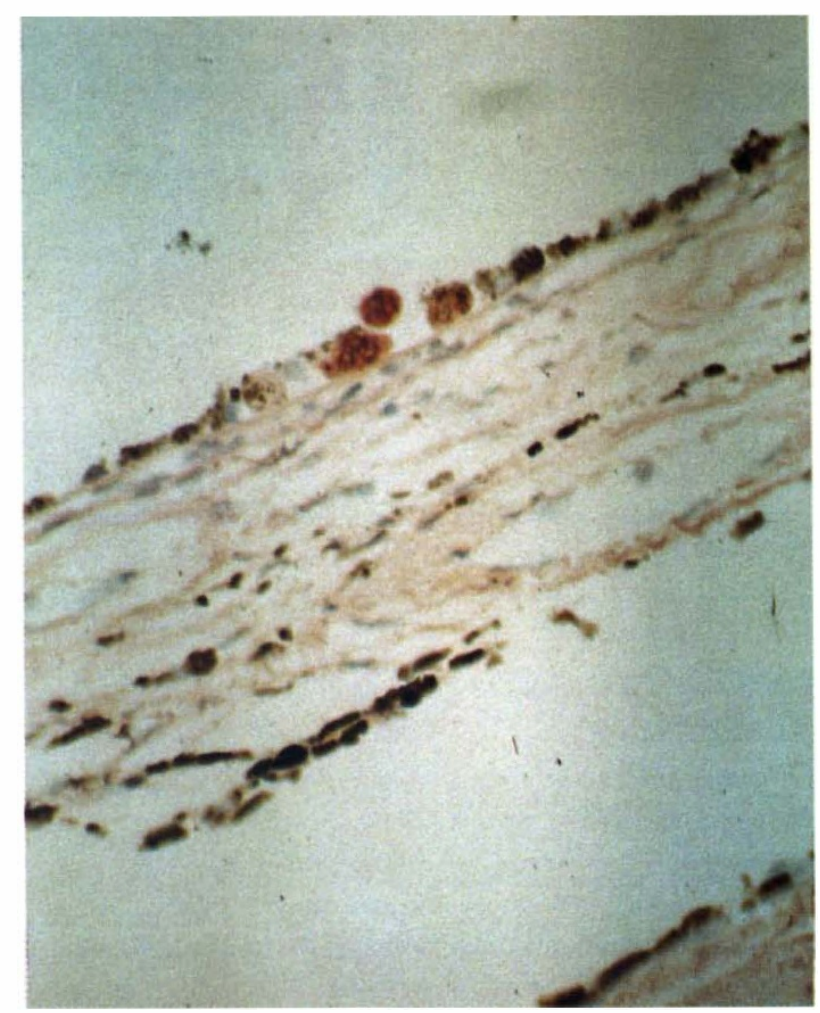

(b)

Fig. 2. (a) In situ hybridisation with a CMV probe shows several cells in necrotic retina staining positive (brown reaction product). (b) Positive retinal pigment cells are also recognisable overlying the artefactually detached choroid. DAB-haematoxylin counterstain, $\times 250$.

thickness of the retina and the retinal pigment epithelium underneath. Occasionally, particularly in the early stages of infection, inclusion-bearing cells were observed in the uvea, both in the stroma and in the endothelial lining of blood vessels.

The histological findings confirmed the presence of CMV retinitis in 14 patients diagnosed antemortem and detected a further 7 cases of microscopical CMV chorioretinitis that had escaped a clinical diagnosis either because the patients had not been examined within the last month of life or because their fundi could not be visualised. The remaining 4 cases did not have clinical notes available.

Microinfarcts and microglial nodules associated with CMV-infected cells were observed in cases with CMV encephalitis.

In all instances, histological results were confirmed by CMV-DNA in situ hybridisation (Fig. 2).

In total, 54 of the 86 patients $(63 \%)$ showed nuclear and/or cytoplasmic inclusions characteristic of CMV in one or more of the sampled tissues. CMV retinitis was the most common ocular infection in this series and accounted for $29 \%$ of cases ( 25 of 86 patients). The frequency of visceral and cerebral involvement was $49 \%$ and 33\%, respectively (Table 2). There were no cases with localisation of CMV limited to the brain (Table 1). The non-ocular anatomical sites most commonly involved in systemic CMV were, in order, the adrenal glands, lungs and trachea, gastrointestinal tract and oesophagus

(Table 3).

Four patterns of ocular CMV infection were identified (Table 1). In approximately $13 \%$ of the patients the eye was the only site of involvement. More often (20\%) CMV retinitis occurred as a part of multiple-site involvement, including viscera and brain. A third pattern was the concomitant involvement of eye and brain only (9\%), while a less frequent pattern (4\%) was that of ocular and visceral CMV infection. When patients with visceral disease were grouped by the number of infected organs (one, two, three, or more than three organs; Table 4), it appeared that all the patients with infection localised to the eye and viscera fell into the group with visceral

Table 2. Distribution and total incidence (TI) (\%) of CMV in our general AIDS population for each site examined, compared with other published series

\begin{tabular}{lcccc}
\hline TI of CMV & This series $(86$ pts) & Pepose $(35$ pts $)$ & De Girolami $(25$ pts) & Morinelli (206 pts) \\
\hline TI of CMV & $63(54 / 86)$ & $60(17 / 35)$ & $52(13 / 25)$ & $56(116 / 206)$ \\
TI of ocular CMV & $29(25 / 86)$ & $34(12 / 35)$ & $32(8 / 25)$ & $46(94 / 206)$ \\
TI of visceral CMV & $49(42 / 86)$ & $60(21 / 35)$ & $24(6 / 25)$ & $33(68 / 206)$ \\
TI of cerebral CMV & $33(28 / 86)$ & $9(3 / 35)$ & $24(6 / 25)$ & $7(15 / 206)$ \\
\hline
\end{tabular}

pts, patients. 
Table 3. CMV infection of non-ocular sites in 86 AIDS patients

\begin{tabular}{lc}
\hline Site & No. of patients \\
\hline Adrenal glands & 30 \\
Respiratory tract & 24 \\
Oesophagus and gastrointestinal tract & 22 \\
Liver and biliary tract & 12 \\
Lymph nodes & 7 \\
Genitourinary tract & 6 \\
Thyroid & 5 \\
Spleen & 5 \\
Other organs or tissues & $<5$ each \\
\hline
\end{tabular}

disseminated disease (more than three infected organs), as did the majority $(64 \%)$ of those who also showed additional CMV encephalitis.

\section{Discussion}

Opportunistic agents may show a tropism for particular tissues. An example of this is the predilection of Cryptococcus neoformans for the meninges. CMV is known to be primarily lymphotropic and neurotropic, although with the progression of the disease virtually all tissues can be infected. In our CMV-infected patients the visceral form alone, with no concomitant ocular and/or cerebral infection, was the main cause of death $(17 / 54 ; 31 \%$; Table 1). CMV retinitis in patients with systemic disease occurred more often in association with encephalitis, rather than in isolation ( $20 \%$ compared with $4 \%$; Table 1$)$. Furthermore, when the correlation between the degree of systemic involvement and ocular disease was considered (Table 4), it appeared that CMV retinitis occurred more often in patients with involvement of three or more visceral organs, either alone $(100 \%)$ or in association with encephalitis $(64 \%)$, possibly indicating that ocular localisation is an uncommon or late manifestation of a generalised infection.

Despite the fact that in the great majority of cases multiple organ involvement appeared to be a prerequisite for the subsequent dissemination to the central nervous system (brain and retina), in 7 patients $(13 \%)$ of the present series CMV retinitis was observed in the absence of a systemic disease, in keeping with other published results. ${ }^{6,7}$ In these patients, ocular infection was therefore not a late manifestation of AIDS, as it had been observed clinically for a period of 2-17 months (average 9 months) prior to the patient's death, and was bilateral in 2 cases. This confirms the predilection of CMV for the retina, whose involvement in this series appeared to be equal to, if not higher, than that of other central nervous system tissues such as the brain. In fact, while the total number of cases with ocular or cerebral infection is similar (25 and 28, respectively), the brain was always infected in association with other tissues and we found no cases with encephalitis only. Our data confirm previous observations by Morgello et al. ${ }^{11}$ who found in an autopsy study of 107 AIDS patients that all their cases with CMV encephalitis had concomitant systemic infection with CMV; furthermore Achim et al. ${ }^{12}$ showed that $57 \%$ of their patients with systemic CMV
Table 4. Number of CMV-infected viscera relative to involvement of the ocular and cerebral compartments

\begin{tabular}{llllc}
\hline Compartment & One site & Two sites & $\begin{array}{c}\text { Three } \\
\text { or more }\end{array}$ & Total \\
\hline Visceral only & $7(41 \%)$ & $6(35 \%)$ & $4(24 \%)$ & 17 \\
Visceral and cerebral & $4(33 \%)$ & $1(8 \%)$ & $7(59 \%)$ & 12 \\
$\begin{array}{l}\text { Visceral, cerebral } \\
\quad \text { and ocular }\end{array}$ & $2(18 \%)$ & $2(18 \%)$ & $7(64 \%)$ & 11 \\
Visceral and ocular & & & $2(100 \%)$ & 2 \\
\hline
\end{tabular}

had CMV encephalitis also. We also observed a definite trend $(42 \%)$ for systemic and cerebral associations of the disease. However, in $9 \%$ of cases CMV was localised in the brain and eye only, with no systemic involvement, showing that these two sites can be primarily infected. Which of the latter two sites was the first to be involved could not conclusively be extrapolated from the clinical data; however, as in this series the cerebral disease was never observed in the absence of other localisations, it is tempting to speculate that CMV may have progressed to the brain from the eye through retrograde infection of the optic nerve. Alternatively, brain and eye infection may have occurred independently via the blood, without prior systemic infection.

Overall, only 16 cases (30\%) in this series manifested concurrent involvement of the brain and eye, demonstrating that the correlation between $\mathrm{CMV}$ retinitis and CMV encephalitis may have been overemphasised. ${ }^{8,13}$ In a postmortem series ${ }^{7} 33$ cases with ocular CMV showed involvement of the optic nerve, which was always limited to its prelaminary portion. Only 2 of these patients had infection involving the cerebrum. Other authors ${ }^{10,14}$ too were unable to demonstrate a correlation between CMV retinitis and CMV encephalitis. Nevertheless, it appears from our data that, when such an association occurs, CMV infection either affects the two organs independently or extends retrogradely to the brain through the optic nerve. As we have never observed areas of active CMV neuritis in the optic nerve tissue remote from the prelaminar or immediately postlaminar zone in eyes with no CMV retinitis, the possibility that CMV may gain direct access to the retina by spreading from an infected optic nerve ${ }^{15}$ is, in our opinion, rather remote. Our results rather support the findings by Roary et al., ${ }^{16}$ who failed to observe cases of solitary optic nerve CMV without contiguous active retinitis.

Although in this study the reported incidence of CMV retinitis relies on gross examination of the eyes, our figures compare with those of other histological (Table 2) and clinical ${ }^{17}$ series. Indeed, processing the central portion of the eyeball to paraffin embedding ensures that more than three-quarters of the retina is available for histological examination, and examination of the calottes of the eyes with a dissecting microscope allows any abnormal area in the peripheral retina to be identified and sampled. Our results demonstrate that histological examination of the eyes may add to the reliability of purely clinical diagnosis. 


\section{References}

1. Yoser SL, Forster DJ, Rao NA. Systemic viral infections and their retinal and choroidal manifestations. Surv Ophthalmol 1993;37:313-51.

2. Henderly DE, Freeman WR, Smith RE, Causey D, Rao NA. Cytomegalovirus retinitis as the initial manifestation of the acquired immune deficiency syndrome. Am J Ophthalmol 1987;103:316-20.

3. Murray HW, Knox DL, Green WR, Susel RM. Cytomegalovirus retinitis in adults: a manifestation of disseminated viral infection. Am J Med 1977;63:574-84.

4. Casale Turu A, Civera AA, Latorre X. Ophthalmic manifestations of acquired immune deficiency syndrome: a study of thirty-four patients. Ophthalmologica 1988;197:113-9.

5. Moeller MB, Gutman RQ, Hamilton JD. Acquired cytomegalovirus retinitis: four new cases and a review of the literature with implications for management. Am J Nephrol 1982;2:251-5.

6. De Girolami U, Hénin D, Girard B, Katlama C, Le Hoang P, Hauw JJ. Etude pathologique de l'oeil et du système nerveux central dans 25 cas de SIDA. Rev Neurol (Paris) $1989 ; 145: 819-28$.

7. Morinelli EN, Dugel PU, Lee M, Klatt EC, Rao NA. Opportunistic intraocular infections in AIDS. Trans Am Ophthalmol Soc 1992;90:96-109.

8. Pepose JS, Holland GN, Nestor MS, Cochran AJ, Foos RY. Acquired immunodeficiency syndrome: pathogenic mechanisms of ocular disease. Ophthalmology 1985;92:472-84
9. Seregard S. Retinochoroiditis in the acquired immune deficiency syndrome: findings in consecutive post-mortem examinations. Acta Ophthalmol (Copenh) 1994;72:223-8.

10. Jensen OA, Klinken L. Pathology of brain and eye in the acquired immune deficiency syndrome (AIDS): a comparison of lesions in a consecutive autopsy material. APMIS 1989;97:325-33.

11. Morgello S, Cho ES, Nielsen S, Devinsky O, Petito CK. Cytomegalovirus encephalitis in patients with acquired immunodeficiency syndrome: an autopsy study of 30 cases and a review of the literature. Hum Pathol 1987;18:289-97.

12. Achim CL, Wang R, Miners DK, Wiley CA. Detection of cytomegalovirus in cerebrospinal fluid autopsy specimens from AIDS patients. J Infect Dis 1994;169:623-7.

13. Holland NR, Power C, Mathews VP, Glass JD, Forman M, McArthur JC. Cytomegalovirus encephalitis in acquired immunodeficiency syndrome (AIDS). Neurology 1994;44:507-14.

14. Faber DW, Wiley CA, Lynn GB, Gross JG, Freeman WR. Role of HIV and CMV in the pathogenesis of retinitis and retinal vasculopathy in AIDS patients. Invest Ophthalmol Vis Sci 1992;33:2345-53.

15. Culbertson WW. Infections of the retina in AIDS. Int Ophthalmol Clin 1989;29:108-18.

16. Roarty JD, Fisher EJ, Nussbaum JJ. Long-term visual morbidity of CMV retinitis in patients with acquired immune deficiency syndrome. Ophthalmology 1993;100:1685-8.

17. Ebert EM, D'Amico DJ. Differential diagnosis of the retinal manifestations of acquired immunodeficiency syndrome. Semin Ophthalmol 1993;8:2-14. 